\title{
Reflexiones en torno al contexto socio-laboral en El Salvador. Situación en los departamentos de La Libertad y La Paz
}

\section{Consideración previa}

Este estudio ha sido elaborado en el contexto del "Programa de Integración y Fomento de Empleo", un proyecto gestionado por-la Deutsche Gesellschaft für Technische Zusammenarbeit (GTZ-Cooperación Técnica Alemana)" y la "Comisión Nacional de la Pequeña y Microempresa (CONAMYPE)"-

\section{Análisis general}

\section{A. Introducción}

Desde que se firmaron los acuerdos de paz en 1992, el "Programa de Integración y Fomento de Empleo" de la Deutsche Gesellschaft für Technische Zusammenarbeit (GTZ) ha estado participando en la organización de cursos de capacitación vocacional en los departamentos de Chalatenango, Santa Ana y Ahuachapán. En una primera etapa se apoyaron los programas de capacitación masiva de reinserción de los desmovilizados a la vida ciudadana y posteriormente, ya en una segunda etapa, se ha continuado en el área de la formación profesional colaborando con diversas instituciones capacitadoras salvadoreñas.

Desde hace algún tiempo, el proyecto está evaluando el impacto de las actividades realizadas y analizando la posibilidad de elaborar instrumentos de capacitación especializados para mejorar la situación laboral también en otros departamentos del país. Pero para ello, es necesario previamente reflexionar sobre el tipo de capacitación que se está realizando en El Salvador. Es necesario saber si la capacitación que se está llevando a cabo actualmente es la más adecuada, si es la que demanda el mercado y si responde a las inquietudes de los beneficiarios. En definitiva, es necesario saber qué es lo que opinan las empresas y los demás 
agentes sociales.

Precisamente, esta es la razón por la que se ha considerado la necesidad de hacer un estudio en profundidad sobre el terreno, previo a la toma de decisiones, que permita conocer de primera mano, todos estos factores. Para realizar esta investigación se han escogido los departamentos de La Paz y de La Libertad, con el objetivo de que un análisis de este tipo sirva como instrumento de apoyo a las futuras acciones de la GTZ tanto en los dos departamentos analizados como en otros departamentos del país a los cuales se les pudiera aplicar algunas de las conclusiones vertidas en el estudio.

Este artículo que presentamos en la revista Realidad de la Universidad Centroamericana José Simeón Cañas, es una sìntesis basada en el informe que hemos elaborado para la GTZ. Tras explicar la metodología que se ha seguido en la elaboración de dicho informe, destacamos los principales aspectos del contexto socio-laboral de El Salvador y analizamos la estructura problemática, las principales iniciativas y las necesidades de capacitación de las zonas visitadas en los departamentos de La Libertad y de La Paz, tras lo cual recogemos, a modo de conclusión, algunas reflexiones sobre los temas analizados y mostramos la bibliografía éstudiada.

\section{B. Metodología}

Para realizar esta investigación, se han seleccionado cuatro zonas de estudio, dos por cada uno de los dos departamentos seleccionados como muestra. En el departamento de La Libertad, estas zonas han sido el municipio del Puerto de La Libertad y el área que va desde Colón-Lourdes hasta San Juan Opico. En el departamento de La Paz, las zonas elegidas han sido el municipio de Zacatecoluca y el área de influencia de la zona franca de El Pedregal.

El estudio de campo se planificó de forma que en cada uno de los municipios escogidos se obtuviera información de todos los sectores e instituciones representativas. Durante los casi tres meses del período de la investigación, se han mantenido entrevistas con los principales agentes sociales, desde alcaldes, hasta gerentes de empresas, presidentes de cooperativas, líderes comunales, directores de escuela, sacerdotes y gerentes de instituciones de crédito. Para realizar esta investigación y conocer así la situación sobre el terreno de manos de sus propios interlocutores, se ha hablado con más de ochenta personas, se han elaborado más de trescientas hojas con todo tipo de anotaciones y se ha leído una amplia cantidad de documentación sobre la situación de la capacitación vocacional en El Salvador.

Como suele ser normal en este tipo de análisis, en cada una de las zonas visitadas, la investigación se ha debido de adaptar a la diversa receptividad de los agentes sociales y a las peculiares circunstancias de los municipios visitados. 
Debido a todos estos factores, en el análisis realizado sobre Zacatecoluca predomina más la visión de la estrategia del municipio frente a la estrategia del sector privado, ya que no se ha podido obtener mucha información del escaso sector empresarial de la zona. Por el contrario, en la zona de El Pedregal predomina el análisis del sector privado empresarial. También en la zona de San Juan Opico-Colón-Lourdes el énfasis recae en el sector empresarial conjuntamente con el sector de los líderes comunales. Finalmente, en la zona del Puerto de La Libertad se nota más que en las otras zonas visitadas, el peso de las cooperativas y de los líderes comunales. Por lo tanto, la investigación se ha realizado de manera que, en su conjunto, sea un bloque compacto y homogéneo y que permita recoger información de todo tipo de instituciones sobre lo que está ocurriendo en los departamentos analizados.

Tras realizar un análisis general de la situación, el estudio pretende proporcionar una radiografía lo más clara posible del contexto socio-laboral en cada una de las zonas visitadas. En definitiva, el objetivo del informe, realizado por la GTZ en El Salvador, pretende buscar respuesta a las siguientes preguntas:

¿Cuál es el problema central del municipio y cuáles son sus problemas derivados?

¿Cuáles son las principales necesidades y obstáculos del municipio?

¿Cuáles son sus fortalezas y debilidades respecto a la creación de empleo?

¿Cuál es la demanda real de mano de obra del municipio?

¿Qué iniciativas se están tomando a nivel municipal y a nivel del sector privado?

¿Cuáles son las principales necesidades de capacitación?

¿Cuál es la opinión de los principales actores sobre la capacitación?

¿Qué agentes capacitadores hay en la zona?

¿Qué recomendaciones y conclusiones se obtienen de todo lo expuesto?

\section{Contexto socio-laboral de El Salvador}

El análisis que hemos realizado sobre estas cuatro zonas, no puede ser extraído de la situación general del país. Actualmente, El Salvador se encuentra en un período de transición hacia la completa normalización de la vida ciudadana. Como consecuencia del retraso que supuso la década de conflicto armado, el país se enfrenta a una serie de retos sociales, económicos y políticos.

En el aspecto social, a las pérdidas en vidas humanas que la guerra ocasionó, se une el millón y medio de personas que tuvieron que salir del país y la amenaza por parte de las autoridades de EEUU de iniciar una política masiva de expulsiones 
de salvadoreños residentes en aquel país. Así pues, faltan recursos humanos y además, el nivel educativo de la población debe ser mejorado. El Salvador necesita hacer un gran esfuerzo en la capacitación y en el desarrollo, para que sus ciudadanos mejoren su nivel de conocimientos y habilidades básicas. Algunas de las cifras macroeconómicas son preocupantes y los índices de desempleo, de economía informal, de pobreza - especialmente entre las mujeres - y de indigencia, son elevados.

Como consecuencia directa de todos estos problemas, ha aumentado la delincuencia juvenil. Las pandillas de delincuentes juveniles — las maras-, que es un fenómeno importado de EEUU, involucra ya a casi 25000 personas; además, tras la guerra, uno de los grandes problemas sociales de El Salvador ha sido la reinserción de los desmovilizados, si bien actualmente, los problemas que puedan tener los antiguos desmovilizados son ya los mismos que los del resto de los ciudadanos.

A todos estos problemas, hay que añadir la crisis en la que se encuentra el sector agrario. El Salvador sigue siendo un país agrícola, sin embargo, la tierra se ha empobrecido mucho en los últimos años, debido a varios factores: el mal uso de los recursos ambientales, la falta de competencia en las actividades económicas agrícolas, el decidido apoyo del Banco de Fomento Agropecuario al comercio en vez de fomentar el sistema agropecuario, y la inadecuada utilización de insecticidas, algunos de los cuales están prohibidos internacionalmente.

No obstante estos datos, El Salvador está inmerso en un proceso de profunda transformación y de modernización. Se están realizando esfuerzos por adaptarse a las reglas que rigen la actual globalización de la economía. Ahora bien, la globalización es un desafío al desarrollo y a la reconversión de la mano de obra, que necesita de pautas y de documentos gubernamentales sobre la estrategia a seguir

El Salvador está realizando esfuerzos por descentralizar su administración pública. En estos esfuerzos por descentralizarse está siendo apoyado por el programa PROMUDE de la GTZ. En la base de la descentralización está la idea de que las comunidades tienen que ser más eficientes y rentables en la administración de ciertos recursos operativos a nivel local, que el propio gobierno central. Sin embargo, aunque esto sea cierto en teoría, se olvida que en El Salvador los municipios son bastante débiles y en muchos casos no están preparados para asumir todas las competencias.

Según hemos podido apreciar, el problema es que con la guerra los municipios perdieron parte de sus competencias que aún permanecen en manos del gobierno central, por lo que pocos son los municipios con verdadera capacidad autónorina de gestión. Además, muchos municipios están en una situación cercana" a la 
banca rota, como resultado de una gran multiplicidad de factores: mala gestión, malversación de fondos, incapacidad recaudatoria, fraude fiscal...etc. Por otro lado, las leyes tampoco favorecen a los alcaldes para que puedan recabar sus impuestos municipales. Así por ejemplo, los polos industriales - las zonas francas - se benefician de los servicios de los municipios pero no contribuyen a su desarrollo al estar sus actividades libres de impuestos. Se crea así una situación de círculo vicioso, ya que como se dice que los municipios no están capacitados, no reciben dinero y los alcaldes como no reciben dinero, no hacen planes municipales.

Lo que está ocurriendo en muchos casos es que la descentralización administrativa, más que ayudar a generar competencias a nivel local, ha contribuido a dejar a su propia suerte a los municipios. Precisamente, para evitar esto, la creación del Consejo Departamental de Alcaldes (CDA) es una iniciativa interesante. El CDA es una asociación gremial de alcaldes, a nivel departamental, financiado por las propias Alcaldías. No es un ente publico. El CDA se crea ante la ausencia de órganos intermedios entre el gobierno y los ayuntamientos. Con esta iniciativa, lo que se pretende es que el CDA sea el organismo que coordine la oferta y la demanda de servicios y financiamientos que fluyen a un departamento. En el futuro se espera que el CDA contribuya a que los municipios se vayan organizando y especializando en aquello para lo que están mas preparados.

Como se verá a lo largo de estas páginas, todos estos problemas están en la base de la investigación realizada. Casi todos los municipios demandan las mismas cosas: mayores ingresos, clarificación de la autonomía municipal y coordinación del sector público para poder lograr la descentralización. Además de estas demandas, cada municipio tiene sus propias necesidades, que en mayor o menor medida, siempre coinciden: mejora de las carreteras de acceso, canalización del agua potable, servicio eléctrico, alcantarillado para las aguas residuales, vertederos de basura, salud y educación. Curiosamente, la solución de todas estas necesidades escapan, en gran medida, a la competencia municipal

Por el contrario, las necesidades de las empresas son diferentes. En general, se ven afectadas también por los problemas de infraestructuras y servicios, aunque reconocen que se han producido grandes avances en los últimos años, en parte debidos a la existencia de las propias empresas en la zona. Además, las empresas suelen estar ubicadas en lugares privilegiados, de fácil acceso, sin problemas de agua ni de luz y con buenas carreteras. Por otro lado, casi todas las empresas se lamentan de que el mercado de trabajo esté poco capacitado, si bien, consideran que no es un gran problema en el caso del personal operario; de hecho, la mayoría han creado sus propios sistemas de capacitación interna. Sí están más preocupadas, sin embargo, ante la falta de personal cualificado para puestos de mayor responsabilidad. 
Como se verá a continuación, precisamente este estudio sobre la Capacitación Vocacional analiza sobre el terreno todos estos temas, que se acaban de observar y además recoge las inquietudes de las empresas y de los demás agentes sociales sobre sus necesidades de capacitación para fomentar el empleo y apoyar al sector de la microempresa a nivel local.

De acuerdo al cuadro de datos estadísticos sobre las zonas visitadas, que hemos elaborado a partir de la información suministrada por las monografías de Cuantificación y Localización de las Necesidades Básicas, se pueden extraer las siguientes consecuencias:

De los siete municipios visitados, el de mayor número de habitantes es Zacatecoluca (57.804), seguido de San Juan Opico (51.701). El municipio de Colón representa unos datos elevados en el número de habitantes (49.570) y en el resto de los demás datos, debido al gran desarrollo de su cantón Lourdes, como se explica a lo largo de este artículo. El Rosario de la Paz (9.797) es el municipio con el menor número de habitantes, aunque alberga en su interior a la zona franca de El Pedregal. Por lo que estos datos cambiarán en el futuro.

Si tenemos en cuenta el nivel de educación de la población en estos municipios, observamos que al hablar de la población analfabeta se altera la relación. San Juan Opico (14.949) es el municipio con mayor población analfabeta seguido de Zacatecoluca (13.901) y de Colón (10.913). Curiosamente el porcentaje de la población analfabeta respecto al total del departamento es aproximadamente el mismo que el de la población total respecto al total del departamento. Por el contrario si se toman las cifras de número de profesores en Zacatecoluca (874) con respecto a San Juan Opico (608) y a Colón (465) se observa que su peso en el porcentaje total del departamento, con relación al número de habitantes es mayor en Zacatecoluca que en San Juan Opico, de lo que se deduce, que en proporción, se está invirtiendo más en Zacatecoluca que en San Juan Opico. Sin embargo, la diferencia entre el número de escuelas entre Zacatecoluca (142) y San Juan Opico (137) es pequeña, pero el peso del porcentaje con relación al total de la población es más alto en San Juan Opico que en Zacatecoluca. Finalmente, el promedio de escolaridad es prácticamente el mismo (seis años) en todos los municipios, con las excepciones de El Rosario y San Pedro Masahuat que es de cinco años. Esta baja escolaridad promedio que se observa en todos los municipios es un factor condicionante del futuro desarrollo de las zonas analizadas, como se verá a lo largo de estas páginas.

Los datos urbanisticos son también un reflejo de la situación en los cantones. Zacatecoluca (12.316) es el municipio de mayor número de viviendas. Sin embargo, es Colón (10.569) el que se encuentra en segundo lugar por encima de San Juan Opico (10.163), lo cual es un factor más que explica el fuerte desarrollo que se está produciendo en la zona. En este caso, el porcentaje del número total de viviendas con relación al total del departamento, coincide con el porcentaje 
de la población total, en todos los municipios, salvo en el caso de San Juan Opico que es ligeramente más bajo, lo que puede indicar una mayor concentración de personas por número de viviendas. En Zacatecoluca, se observa además que en más del 50\% de las casas no hay servicios de recolección de basuras (9.728), ni desagüe de aguas negras (8.801) ni cañería de agua potable (7.077). En el extremo opuesto, en El Rosario de La Paz, que es el municipio más pequeño, también se produce la misma situación. Más del $50 \%$ de las casas no tienen cañerías de agua potable (1.482), ni desagües (1.586) ni servicios de recogida de basuras (1.732). Como se puede observar en el cuadro, esta situación empeora en los municipios de San Pedro Masahuat, Colón y Puerto de La Libertad. En el caso de San Pedro Masahuat debido a su problema de aislamiento, en el caso de Colón debido a desequilibrios en su planificación por su rápido crecimiento y en el caso del Puerto, debido al deterioro de muchos de sus cantones.

Si analizamos ahora la situación de la demanda laboral, observamos que el nivel de población económicamente activa en Colón (17.146) es casi el mismo que el nivel de PEA en Zacatecoluca (19.887), sin embargo el peso de la PEA en Zacatecoluca respecto al total de su población es mayor que en Colón, que al parecer es una población más joven, precisamente por la fuerte corriente migratoria que se está produciendo hacia esa zona. En la mayoría de los siete municipios visitados, la mayor parte de la PEA está trabajando en el sector de la agricultura, lo que demuestra el fuerte peso que este sector sigue teniendo en El Salvador. La única excepción es Colón, en donde la mayor parte de su PEA está concentrada en el sector industrial (4.709) si bien con un fuerte peso del sector agrícola (3.855), lo cual refleja el rápido cambio en la demanda de trabajo que se está produciendo en esa zona. Lógicamente, es en el sector del servicio doméstico donde hay menos personas trabajando, si bien en San Juan Opico esta fuente de trabajo (745) casi iguala a las personas que están trabajando en el comercio (986). Después del sector del servicio doméstico, el sector del comercio es el que menos parte de PEA demanda, si bien, en claro ascenso. Así en Zacatecoluca la parte de la PEA dedicada a este sector iguala a la parte de PEA dedicada a la industria (3.312). En San Juan Nonualco está incluso por encima (600) de la parte de PEA dedicada a la industria (590).

Al analizar el sector empresarial llama la atención el gran número de microempresas de menos de cuatro empleados (1.459) en Zacatecoluca en relación a los otros municipios, así como su gran peso en relación al total del departamento (42\%). Una situación muy similar ocurre en Puerto de La Libertad que ocupa el segundo lugar (810) por encima de Colón y de San Juan Opico. Estos datos explican de forma clara el grave problema de venta callejera al que se enfrentan ambos municipios, como veremos en la segunda y tercera parte de esta investigación. 
Finalmente, de acuerdo a los datos que aparecen en el cuadro, San Pedro Masahuat (57\%) es el municipio con mayor peso del empleo agrícola sobre el total de empleos, seguido de San Juan Opico (56\%). Colón y Puerto de La Libertad (30\%) ocupan los últimos lugares.

Para obtener una mejor respuesta a todas estas preguntas, en cada una de las cuatro zonas objeto de estudio se han analizado tres temas fundamentales: la estructura problemática, la estructura de los objetivos y la estructura de las necesidades de capacitación. A continuaciòn, se muestra un resumen de los principales aspectos de la investigación, respecto a los mencionados temas.

\section{Departamento de La Libertad}

\section{Zona San Juan Opico-Colón-Lourdes}

Esta región está experimentando en los últimos años un importante desarrollo económico y social desde que se crearon las zonas francas de Export Salva y American Park y empezaron a llegar las empresas maquiladoras (empresas del sector textil).

\section{Estructura problemática}

\section{San Juan Opico}

El municipio de San Juan Opico tiene una extensión de aproximadamente $219 \mathrm{~km}^{2}$ y está formado por 27 cantones y 101 caseríos.

Como se puede apreciar en el gráfico de la estructura problemática de la zona, en San Juan Opico el problema central es desarrollar las infraestructuras y las comunicaciones de la zona Norte. Esta parte es la más pobre y los caminos y carreteras vecinales están en mal estado. El desarrollo de las comunicaciones en esta zona es básico para que después empiecen a llegar los otros servicios que también faltan: salud, agua, energía eléctrica...etc. San Juan Opico tiene otros problemas de deterioro general, pero en cualquier caso ese deterioro es menor que en otros municipios visitados. Como se verá a continuación, el resto de los problemas de San Juan Opico difieren de la zona del municipio de la que se hable (Norte, Sur o Valle).

La zona Norte es la zona prioritaria de actuación. Se trata del área más apartada y con menor desarrollo del municipio. Es una zona de muy difícil acceso y con serias diferencias de agua y electricidad. La parte más deteriorada de esta zona es la ocupada por los cantones Buena Vista, Nombre de Dios y el Caserío Veracruz. Una buena parte de la gente en los cantones de la zona Norte 


\section{PRINCIPALES DATOS ESTADISTICOS}

\begin{tabular}{|c|c|c|c|c|c|c|c|c|c|c|c|c|c|c|c|}
\hline & \multirow[b]{4}{*}{ CONCEPTO } & \multirow{3}{*}{\multicolumn{2}{|c|}{ ZACATECOLUCA }} & \multicolumn{6}{|c|}{ DEPARTAMENTO DE LA PAZ } & \multicolumn{6}{|c|}{ DEPARTAMENTO DE LA LBERTAD } \\
\hline & & & & \multicolumn{6}{|c|}{ ZONA DE EL PEDREGAL } & \multicolumn{4}{|c|}{$\begin{array}{l}\text { ZONA DEL TRIANGULO DE } \\
\text { ORO }\end{array}$} & \multirow{2}{*}{\multicolumn{2}{|c|}{$\begin{array}{l}\text { PUERTO DE LA } \\
\text { WBERTND }\end{array}$}} \\
\hline & & & & \multicolumn{2}{|c|}{ EL ROSAPIO } & \multicolumn{2}{|c|}{$\begin{array}{l}\text { SNN PEDRO } \\
\text { MMSAHUAT }\end{array}$} & \multicolumn{2}{|c|}{$\begin{array}{l}\text { SNN JUAN } \\
\text { MONUALCO }\end{array}$} & \multicolumn{2}{|c|}{ SuM JUNM } & \multicolumn{2}{|c|}{ colon } & & \\
\hline & & Total & $\% \cdot$ & Total & $\% \cdot$ & Total & $\%$ * & Total & \%* & Total & \%* & Total & $x_{*}^{*}$ & Total & $x^{*}$ \\
\hline & N Tod Hebilanters & 5,004 & $\boldsymbol{x}$ & Q.त्र & 4 & 21, סू & - & 10.27 & 4 & G,जo & $\Phi$ & Q51 & $\boldsymbol{D}$ & ס्र & 7 \\
\hline \multirow{4}{*}{ 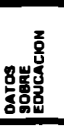 } & Porition andates & 13501 & 2 & 200 & 4 & Q.2. & 11 & 260 & 4 & 140 & D & 10.93 & - & $2 \times 3$ & - \\
\hline & Nimero pridesorits & 874 & $\mathbf{z}$ & $\mathbf{m}$ & 7 & 20 & 7 & 115 & 4 & $\overline{6}$ & - & 6 & 7 & $\overline{3}$ & - \\
\hline & Nimero esomelas & 12 & $\mathbf{z}$ & 3 & 5 & 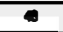 & 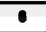 & $\mathbf{D}$ & 5 & 13 & 2 & - & - & (I) & 7 \\
\hline & Promedo ascitider & - & & 5 & & 5 & & 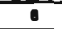 & & - & & - & & - & \\
\hline \multirow{8}{*}{ 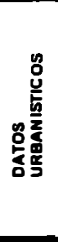 } & Nimero bod iniendes & 12316 & $\boldsymbol{x}$ & 2000 & 4 & 400 & - & 2003 & 4 & 19,16 & D & 1050 & $\Phi$ & $7 \mathbf{8}$ & 7 \\
\hline & Sin conter ni agra potede & $7,0 \mathrm{~T}$ & 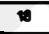 & 1,40 & 3 & $4 \infty 07$ & 11 & 1,001 & 5 & 7310 & 10 & 4016 & $\bullet$ & 4910 & - \\
\hline & Sin senvicies saniterios & 200 & 1 & $\infty$ & 3 & 1 is & 12 & 50 & 4 & 100 & 2 & $F$ & 3 & 10 & $\bar{x}$ \\
\hline & Sin desegie do egens ropres & 201 & 10 & $1.5 \mathrm{ses}$ & 3 & $2 \pi$ & (0) & 10 & 4 & 0 & ט & $7, \mathrm{Mg}$ & 2 & 20 & - \\
\hline & Sin sonvers de racolection de basuras & 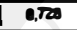 & 21 & 1.72 & 4 & sen & 10 & 2141 & 5 & 0,10 & 2 & 20 & 2 & ص & 7 \\
\hline & Con pos de vierta & 5,72 & 21 & $\infty$ & 3 & $2 \pi$ & w & 1.180 & 4 & $4, m$ & 2 & 326 & $\bullet$ & $31 n$ & $\bullet$ \\
\hline & Sin etricidar & 4,747 & $\mathbf{D}$ & $\mathbf{s}$ & 3 & 190 & $\bullet$ & 1,000 & 5 & 3,00 & 2 & $1 . \pi$ & 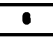 & 200 & 7 \\
\hline & Sin exs en propided & 4,724 & D & $\Phi$ & 5 & 1,312 & 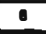 & $\sqrt{50}$ & 5 & 3,10 & $\bullet$ & 40 & w & $2 \mu 0$ & $\bullet$ \\
\hline \multirow{6}{*}{ 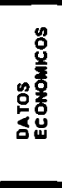 } & 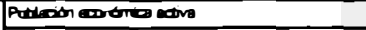 & rage & $\mathbf{z}$ & 3106 & 4 & atio & - & यक्ण & 3 & Sape & - & 17.16 & iv & rasin & \\
\hline & 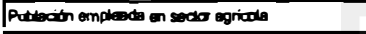 & QS97 & D & 1,140 & 3 & 200 & 11 & 1,300 & 4 & क्जा & 8 & F.5 & 8 & soro & $\overline{0}$ \\
\hline & Potracion anplesile on ed sector indaches & 3,312 & 2 & 5 & 5 & 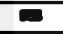 & 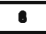 & 5 & 5 & 2003 & - & $4 \pi$ & M & $1, \pi$ & $\bullet$ \\
\hline & 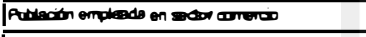 & 2,312 & 3 & $\mathbf{0}$ & 5 & $5 \mathrm{sin}$ & - & $\mathbf{m}$ & 7 & $\boldsymbol{\sigma}$ & 4 & $2 \times 2$ & 2 & 1 1A10 & 7 \\
\hline & 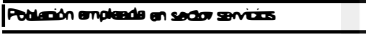 & $4 \pi 0$ & $\mathbf{3}$ & 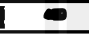 & 4 & $\mathbf{\infty}$ & e & an & 5 & $2=8$ & 7 & 2010 & 7 & 18 & 5 \\
\hline & 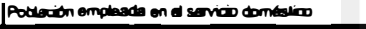 & - & $\Xi$ & 2 & 5 & 10 & - & 115 & 4 & 780 & - & 1004 & - & a & 7 \\
\hline \multirow{5}{*}{ 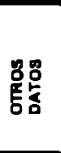 } & 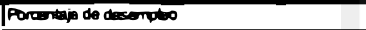 & & 5 & & - & & & & 7 & & 0 & & D & & 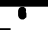 \\
\hline & 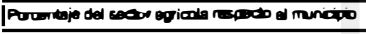 & & 34 & & 0 & & $\mathbf{I}$ & & $\infty$ & & 5 & & D & & $\overline{3}$ \\
\hline & Nineor doenters & $\pi$ & & 2 & & $\mathbf{M}$ & & - & & 4 & & $\bullet$ & & $\mathbf{2}$ & \\
\hline & 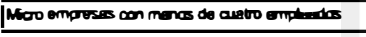 & $1, \infty 00$ & e & 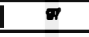 & 3 & 117 & 3 & 20 & - & $3 \mathbf{3 0}$ & 4 & 0 & $\bullet$ & 10 & 11 \\
\hline & 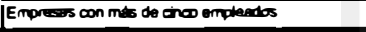 & $\infty$ & 2 & 4 & 3 & (1) & - & 1 & 1 & 15 & 3 & D & $\bullet$ & 8 & - \\
\hline
\end{tabular}

Fuente: Elaboración propia a partir de las monograflas de "Cuantificación y Localización de las Necesidades Básicas (dalos censales)". Gadierno de El Salvedor. Enero

G 1996. 
de San Juan Opico, sigue viviendo de la agricultura. Sus habitantes se dedican al ganado y a cultivar el maíz, el maicillo y el frijol. La excepción es la parte baja de esta zona, ocupada por la cooperativa de Talcaulhuya, en donde hay abundante ganado lechero, mejor comunicación y por lo tanto, más fácil acceso a los servicios.

La zona Sur tiene mejor acceso, más recursos y es bastante más verde que la zona Norte y aunque el acceso a esta zona es también problemático, las carreteras están en mucho mejores condiciones de accesibilidad. Estos cantones poseen alumbrado eléctrico en las casas y suficiente agua, que bombean de los pozos. Sus habitantes también se dedican a la agricultura y cultivan los mismos productos: el maíz, el frijol y el maicillo. Las Lomas de Santiago es uno de sus principales cantones, en donde viven alrededor de unas 4000 personas.

Las comunidades del Valle del Cerén están situadas en una zona considerada como centro magnético por los mayas, como lo muestra su proximidad a las pirámides de San Andrés. Es una zona con excelente acceso, al pie de la carretera general y que alberga a la comunidad Tec-Pan, el Sitio del Niño, San Andrés y la Flor Amarilla. La urbanización de esta zona va a crecer enormemente en los próximos años, lo que va a dar lugar a un amplio polígono industrial de desarrollo en el municipio de San Juan Opico, por lo que los problemas de esta zona son producto de su rápido crecimiento. Disponen de manto de agua freática abundante y de red electrificada; y como se puede observar, la situación del mercado laboral en la zona del Valle de San Andrés es bien diferente a la de otras zonas del municipio. En Tec-Pan, la gente trabaja fuera de la comunidad y son pocos los que viven de la agricultura, casi todos son albañiles, mecánicos, empleados en oficinas y motoristas..

En resumen, el análisis de la estructura problemática de los cantones de San Juan Opico muestra claramente la diferente situación en que se encuentran las tres zonas. Así por ejemplo, mientras que en el Norte, su objetivo en los próximos años es conseguir que les llegue la electricidad; en el Valle del Cerén su objetivo es tener una Universidad en los próximos 10 años.

\section{B. Colón-Lourdes}

El municipio de Colón tiene una extensión aproximada de $84 \mathrm{~km}^{2}$ y cuenta con 12 cantones y 37 caseríos, de los que Lourdes es el cantón más importante.

El caso de Colón-Lourdes es bien distinto al de San Juan Opico, ya que su problema central es doble: por una parte, Colón pese a su escaso desarrollo y pequeño tamaño, es la cabecera del municipio, mientras que Lourdes es aún un cantón, pese a ser una zona más poblada y con un mayor potencial de desarrollo; por otro lado, gran parte de los problemas que tiene Lourdes son producto de su 
rápido crecimiento que ha impedido absorber a tanta población en tan poco tiempo por la falta de infraestructuras adecuadas

Las consecuencias de su rápido crecimiento acelerado, no planificado adecuadamente, han traído consigo una serie de problemas colaterales de tipo social, sanitario, medioambiental y de falta de servicios públicos. Lourdes es además, un asentamiento de gente muy afectada por la guerra. Ambas causas se han unido para producir la situación conflictiva en la que se encuentra Lourdes actualmente. Uno de sus grandes problemas es la delincuencia, pero también hay una gran desintegración familiar como consecuencia de los problemas económicos y de que muchos niños carecen de padres; además, en Lourdes las aguas negras circulan por las calles porque se carece de un sistema de alcantarillado, lo que facilita la existencia de las enfermedades gastrointestinales y diarreas; por otro lado, la contaminación vehicular está creando grandes problemas respiratorios.

\section{Sector empresarial.}

En la investigación se ha observado que los principales problemas que tienen los empresarios en la zona San Juan Opico-Colón-Lourdes, son la falta de un vertedero adecuado de basuras; la inadecuada red telefónica; el aumento de la delincuencia en la zona que provoca frecuentes asaltos a los camiones cargados de mercancías; y el encarecimiento del suelo.

Las empresas que necesitan contratar más mano de obra son las empresas maquiladoras. En el Parque de Export Salva cada empresa maquiladora disponen de 250 a 780 trabajadores, lo cual supone unas 3500 personas trabajando en todo el Parque. Estas empresas no tienen especial problema en contratar a nuevos operarios ya que algunas reciben más de 200 solicitudes diarias, aunque solo pueden dar trabajo a un diez por ciento de las solicitudes, como máximo. Cada maquila recluta a su propio personal y le hace las pruebas que estima oportunas.

Por lo que se refiere a las empresas que no trabajan en el sector de la maquila, la política de contratación de personal es bien distinta. En general, prefieren contar con una fuerza de trabajo más estable, por eso su política es proteger el puesto de los trabajadores, incluso algunas cuentan hasta con un sindicato. El promedio de permanencia de los trabajadores en estas empresas es alto y los sueldos que reciben sus trabajadores están por encima de la media de sueldos que se pagan en las maquilas.

\section{Iniciativas que se están tomando en la zona}

A nivel municipal, la Alcaldía de San Juan Opico ha preparado un plan de acciòn en cinco puntos: modernizar su propio funcionamiento; elaborar un plan de desarrollo comercial de Opico que favorezca la generación de microempresas; 
desarrollar las comunicaciones de la Zona Norte del municipio; elaborar un proyecto turístico sencillo en la Zona maya de Joyas de Cerén, y detener el desempleo a través de impulsar los talleres de capacitación vocacional. Para conseguir estos cinco objetivos del plan de trabajo, la Alcaldía espera contar con la participación ciudadana. Por lo que respecta al municipio de Colón, se observa que el cantón de Lourdes es una zona con un enorne potencial de desarrollo y que está creciendo rápidamente, por lo que todos los esfuerzos municipales deben ir dirigidos a solucionar los problemas de este gran cantón.

Las empresas que están operando en esta zona, han adoptado diferentes iniciativas entre las que destacan: aumentar la expansión de su producción y la innovación tecnológica; diversificar la producción; aumentar las exportaciones; y prepararse para la competencia ante la llegada de nuevas empresas. Además, la zona comprendida entre San Juan Opico y Colón-Lourdes está considerada por el Gobierno como el V Polo de Desarrollo Industrial del Gran San Salvador, aunque de hecho, esta región no pertenezca al Gran San Salvador. Por tal motivo, son muchas las posibilidades de desarrollo.

\section{Necesidades de capacitación}

El municipio de San Juan Opico quiere impulsar los talleres de capacitación como el mecanismo más adecuado para fomentar el empleo y cumplir así con uno de sus principales ejes estratégicos de actuación. Las áreas o sectores principales de capacitación ya identificados por la Alcaldía son: carpintería, confección y sastrería, obra de banco, albañilería, electricidad, informática y mecánica automotriz. Estas áreas coinciden con las principales inquietudes y necesidades de capacitación mostradas en los cantones visitados.

Por otro lado, las empresas maquiladoras de la zona, consideran que sería muy interesante instalar en los alrededores, un centro de capacitación que fuese flexible y de carácter abierto, ya que el centro de capacitación más cercano es el ITCA, pero está muy lejos. En la práctica, las empresas entrevistadas suelen resolver sus necesidades de capacitación de forma interna. Las maquiladoras suelen necesitan personal especializado y mecánicos de planta para hacer frente a la reparación continua del equipo, sin embargo se encuentran con dificultades para encontrar a gente capacitada. Estas empresas reconocen que estos especialistas exigen salarios más elevados, sin embargo, no se les puede dar mejores salarios porque los precios los imponen los clientes de EEUU

Por el contrario, las empresas que no pertenecen al sector de la maquila, como disponen de unos ciclos de rotación de personal más bajos, tienen menos necesidades de capacitación. En general, también tienen sus propios sistemas internos de capacitación del personal, si bien se observa que el futuro de muchas de estas empresas pasa por aumentar su nivel de tecnología y disminuir el de la 
mano de obra.

Son varias las instituciones que han organizado cursos de capacitación en la zona: el ITCA, el Instituto Santa Cecilia, AGAPE, IOPIC, CIT, ASALDI...etc. También en San Juan Opico, la Casa de la Cultura y el Banco de Fomento Agropecuario han promovido cursos a nivel de microempresas y la Iglesia Católica estuvo dando cursos de mecánica de banco y de confección.

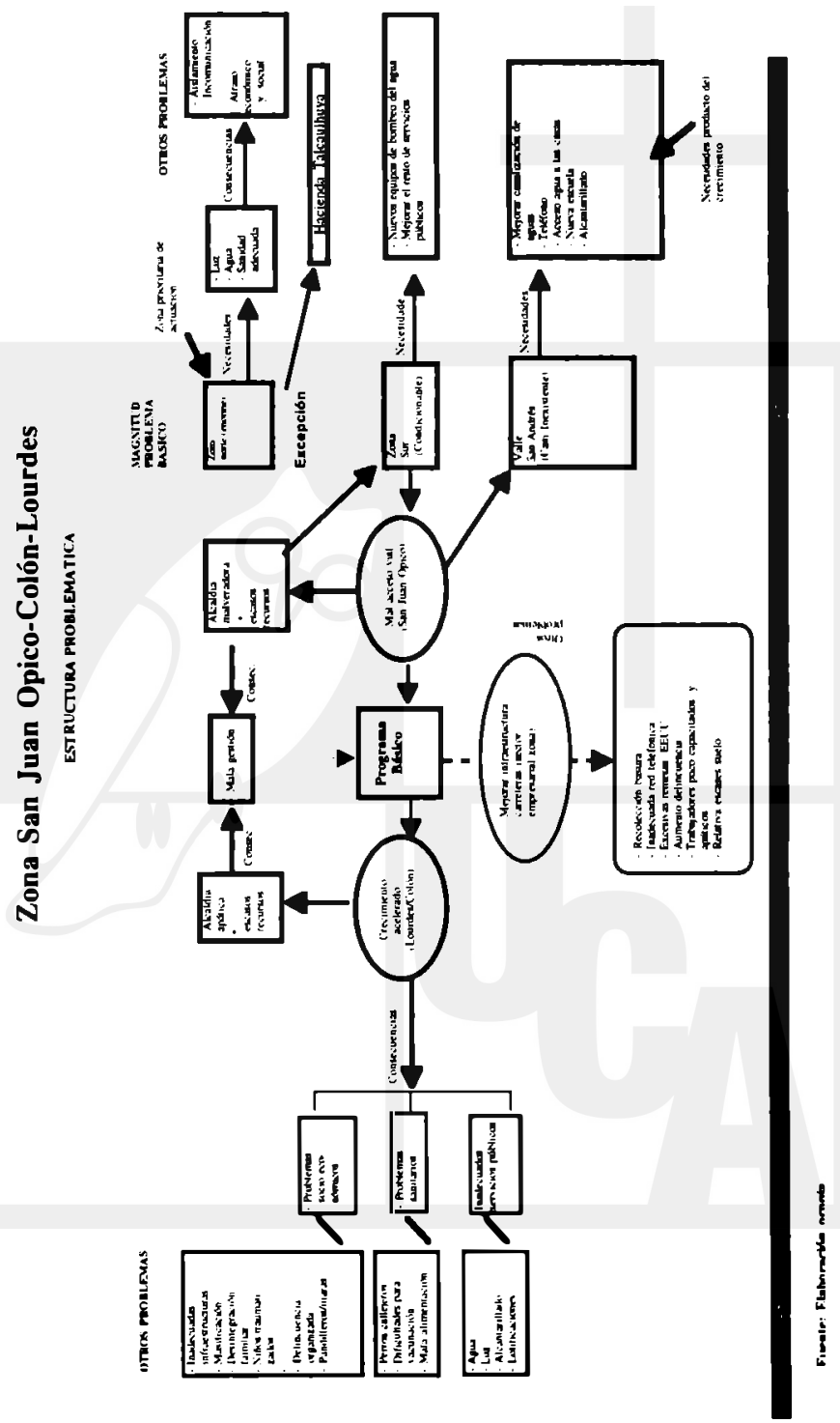




\section{Puerto de La Libertad}

\section{A. Estructura problemática}

El municipio del Puerto de La Libertad tiene una extensión de $162 \mathrm{~km}^{2}$ y está dividido en 10 cantones y 38 caseríos. La investigación sobre Puerto de La Libertad ha recaído principalmente sobre los líderes comunales de los cantones y sobre los presidentes de las cooperativas agrícolas, pesqueras, de crédito y de servicios.

Segùn nuestros interlocutores, Puerto de La Libertad tiene varios problemas principales, como son: la falta de recursos económicos, el mal funcionamiento de la administración municipal, la pobreza ciudadana y la contaminación ambiental. De todos estos problemas, sin duda el de la falta de recursos económicos es el más grave, porque condiciona la solución de los demás problemas y por lo tanto, es el que necesita ser resuelto de forma más inmediata. En el caso del Puerto de La Libertad, el problema se agrava porque hay pocas empresas instaladas en la zona, si bien hay bastantes registradas en el municipio, a efectos fiscales, pero que no pagan impuestos a la alcaldía.

Como se puede observar en el gráfico de la estructura problemática, todos los problemas están interconectados. La falta de recursos económicos se produce por un inadecuado funcionamiento de la administración municipal, que a su vez genera una incapacidad del Estado, a nivel local, de recaudar impuestos, lo que favorece el fraude fiscal y por lo tanto que las instituciones no se registren o que las registradas no paguen sus impuestos, lo cual lleva a la falta de ingresos que hace que no funcionen adecuadamente los servicios municipales y que explican, entre otras causas, una cierta desorganización ciudadana, que se produce ante la falta de una adecuada infraestructura de transportes. La situación que se acaba de describir contribuye, sin duda, a generar pobreza ciudadana. Además, en el municipio de La Libertad la mayor parte de la gente vive de la pesca y del sector informal del comercio.

Los cantones del municipio del Puerto de La Libertad tienen problemas derivados muy similares a los de los cantones de la zona Norte de San Juan Opico. Esta zona es incluso más árida y montañosa y también de accesibilidad difícil. Hay tres problemas básicos: el acceso, el agua y la electricidad.

En esta zona se han visitado los cantones El Cimarrón y Tepehagua y los caseríos El Salamo y Las Mesas. Se han observado sus problemas de abastecimiento de agua y de electricidad. El cantón es una zona bastante árida donde es difícil el cultivo agrícola. Los habitantes de estos lugares viven de la venta callejera en El Puerto y del servicio doméstico, si bien muchos trabajan en Santa Tecla o en Ciudad Merliot. Además, en los cantones más alejados de la carretera general, la gente debe recorrer a pie varios kilometros hasta llegar al 
cruce con la ruta de autobuses hacia San Salvador.

También las cooperativas de la zona deben hacer frente a una serie de problemas. Las cooperativas de pescadores carecen de fondos para hacer frente a sus necesidades de pesca. Tradicionalmente, los miembros de la cooperativa se han dedicado a la pesca artesanal. Con esta técnica de pesca, han estado pescando curvina, pargo, tiburón pequeño, anguila, macarena, tamalitos, meros y pámpanos. El problema es que la pesca artesanal, aunque es una técnica de pesca menos agresiva con la fauna marina, está perdiendo terreno ante las nuevas técnicas de arrastre de la pesca industrial. Por otro lado,. la cooperativa de Motoristas y Cobradores de autobuses, necesitan renovar la flota de autobuses, así como elaborar una nomenclatura nueva y construir una nueva terminal de autobuses.

\section{B. Iniciativas que se están tomando en el municipio}

Las estrategias de la nueva Alcaldía se basan en dos ejes principales: un nuevo estilo de gobernar y el fomento de la participación ciudadana. Los principales temas que se están abordando son la ordenación del funcionamiento de la Alcaldía; la recuperación del Patrimonio Nacional; la mejora de los espacios verdes y de esparcimiento; la reorganización de la actividad recaudatoria del municipio; la realización de pequeñas obras que generen impacto en la población y la promoción del desarrollo integral en las comunidades

Los cantones del Puerto de La Libertad también están tomando sus propias iniciativas para solucionar sus principales problemas de acceso, agua y luz. En cuanto a las cooperativas, tienen serios problemas de gestión y se mantienen gracias a la ayuda internacional que reciben. Las cooperativas de pescadores desean construir una fábrica procesadora y enlatadora de productos marinos, que sea un centro de acopio para procesar came de tiburón y de otros pescados y que enlate y envase el pescado para distribuirlo en el extranjero.

El sector turístico es uno de los sectores con más posibilidades de desarrollo en la zona. El municipio cuenta con varias playas atractivas y de fácil acceso, que podrían ser desarrolladas en el futuro, como son: El Obispo, Majahual, Conchalío, La Libertad y San Diego. Al parecer, hay además varios proyectos para potenciar la zona, como es la construcción de una autopista que enlace en quince minutos El Puerto con la capital; o la construcción de un hotel de cinco estrellas. Sin duda, estos factores contribuirían a potenciar el turismo..

\section{Necesidades de capacitación}

Se ha observado que se necesita capacitación en el sector del turismo, en el sector pesquero y en el comercio. Esta capacitación es necesaria tanto en la zona urbana del Puerto de La Libertad, como en los cantones, en las cooperativas y 
en las empresas. Además de estas actividades, al parecer, hay demanda de talleres vocacionales para capacitar a la gente en mecánica automotriz (electricidad); electricidad industrial; mecánica diesel pesada y capacitación a empleados del mercado.

Junto a estos cursos generales de capacitación, en los cantones se demandan cursos de carpintería, costura, electricidad, mane jo de autobuses, tallado, sastrería, peluquería, cosmética, informática, corte y confección y mecánica.

Por otro lado, según se nos indica, las cooperativas de pescadores necesitan capacitación en la técnica de la pesca industrial, camaronera y de altura, así como formar a sus asociados en el conocimiento de las técnicas de congelación, proceso de enlatado y exportación del pescado. También necesitan recibir diversos cursos accesorios de capacitación en ventas, administración, Consejos de Administración, reparación de embarcaciones de fibra de vidrio, reparación de motores marinos y cooperativismo.

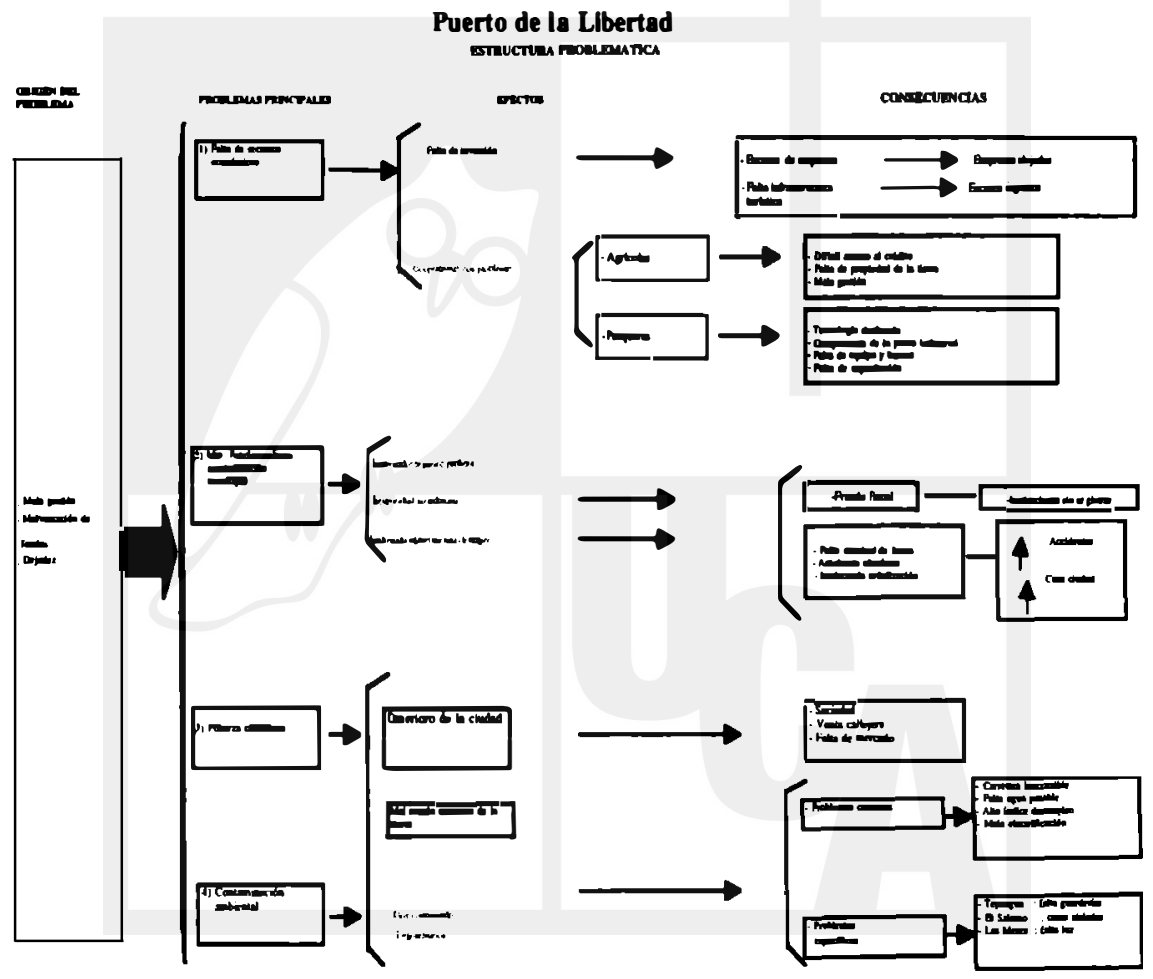




\section{Departamento de La Paz: Zacafecoluca}

\section{A. Estructura problemática}

La ciudad de Zacatecoluca es la capital del departamento de La Paz y está situada a $63 \mathrm{~km}$. de San Salvador. El municipio de Zacatecoluca tiene una extensión de $425,69 \mathrm{~km}^{2}$ y está formado por 43 cantones y 77 caseríos.

El problema central del municipio de Zacatecoluca es la inadecuada gestión de los servicios públicos que se ha realizado durante los últimos años, junto con una deuda actual acumulada de 2.553 .000 colones. Como consecuencia de esta situación, hay tres problemas que son realmente graves en este momento: la falta de un mercado de abastos, la acumulación de la basura, y el mal acceso vial a Zacatecoluca. Junto a estos problemas principales hay otros problemas derivados como son: la posición de debilidad en la que se encuentra la administración municipal, la canalización del agua potable y la escasez de recursos sanitarios.

Se carece de un mercado de abastos estable y regulado por la municipalidad, que solucione el grave problema de la venta callejera en la ciudad de Zacatecoluca, si bien, para hacer frente a esta situación, la nueva alcaldía ya tiene previsto edificar un nuevo mercado. La acumulación de basura es otro de los grandes problemas de la municipalidad de Zacatecoluca. Actualmente hay 27 basureros no regulados y dispersados al interior del municipio de Zacatecoluca, que son foco de infecciones y que juegan un efecto importante en la contaminación de los ríos.

Además, la falta de una carretera de acceso en buen estado genera también una serie de problemas añadidos, ya que no solo es un obstáculo para el incremento del comercio, sino que dificulta la instalación de nuevas empresas. A este mal acceso vial se une el hecho de que las calles de Zacatecoluca están ocupadas por la venta callejera y se carece de una señalización vial adecuada y de paradas de autobuses reglamentadas.

Otro de los grandes problemas es la falta de un sistema adecuado de agua potable. Se carece de bocas o fuentes de agua en las calles en las que venden los comerciantes de las ventas callejeras. El problema no es solo de la ciudad, sino de todo el municipio y se agrava en los cantones por falta de un servicio médico adecuado.

En los últimos años se han desarrollado en Zacatecoluca varios negocios, pero hay fábricas que han fracasado. Los negocios que existen en Zacatecoluca, como Super Selectos y el Pollo Campero, o las instituciones como el CENTA y la fábrica Piscícola, aunque importantes, no pueden absorber, por sí solas, la mano de obra solicitada, así que mucha gente se va a trabajar a las maquilas. 
Además, con la guerra, mucha gente se acercó a Zacatecoluca, por lo que actualmente se empieza a producir un cierto desarrollo por la carretera del litoral.

La falta de grandes empresas en los alrededores de Zacatecoluca es evidente y eso hace que mucha gente busque trabajo en la zona de El Pedregal, en San Vicente o en San Salvador, con la consiguiente pérdida de recursos humanos capaces de contribuir al desarrollo de la ciudad. Por tal motivo, Zacatecoluca carece de un fuerte sector microempresarial, a pesar de que se han abierto bastantes negocios en los últimos años. La única gran empresa de los alrededores es Quesos Petacones.

La mayor parte de las iniciativas enunciadas en la Plataforma Municipal tienen un efecto indirecto en el empleo. Se contempla incluso, la posibilidad de crear una nueva zona franca en los alrededores. Con todo, los principales sectores económicos del municipio de Zacatecoluca son el cultivo del café, los cereales, la producción ganadera, la caña de azúcar y la pesca. También se produce panela, productos lácteos (quesos petacones), comidas típicas (pupusas de Olocuilta) y artesanías. Así pues, la producción tradicional de Zacatecoluca es de carácter agropecuario, si bien, se observa un aumento de la actividad comercial..

\section{B. Iniciativas que se están tomando en el municipio}

A corto plazo, la alcaldía de Zacatecoluca, tiene dos objetivos generales: generar confianza en la población sobre la nueva gestión municipal y tomar el control institucional de la alcaldía. Para ello pretenden llevar a cabo una estrategia transparente, de contacto directo con los ciudadanos. Al mismo tiempo, se están buscando apoyos en organismos internacionales, se han hecho estudios para llevar la electrificación a varias comunidades, se está hablando con los vendedores callejeros para ubicarlos en otro lugar y se va a hacer un nuevo diseño del parque central.

A nivel privado, la Caja de Crédito es un actor que puede jugar un efecto dinamizador en la actividad comercial del municipio de Zacatecoluca, ya que se trata de una cooperativa de responsabilidad de capital variable, pero que también funciona como sociedad anónima. Los sectores que más apoya esta Caja son: el comercio en todas sus vertientes, tanto a vendedores callejeros como a comerciantes con negocios más estables; y los talleres industriales, a través de fondos FOMMI.

Por otro lado, la Casa de la Cultura de Zacatecoluca también está llevando a cabo diversas iniciativas. Su objetivo es la recuperación de las raíces y de la cultura popular local viroleña, además de acoger en su sede a la Biblioteca Municipal. Esta institución alberga el fondo bibliográfico de la Biblioteca Municipal compuesto por casi 6000 libros antiguos y una pinacoteca formada 
por más de 100 cuadros donados por artistas locales, así como esculturas, maquetas y artesanías de diverso tipo.

\section{Necesidades de capacitación}

- En el municipio se observa que existen necesidades de capacitación en los sectores agropecuario, empresarial y de la microempresa, principalmente.

La nueva alcaldía, en su documento de Plataforma Municipal expresamente dice que "se va a promover la implantación de escuelas vocacionales en las áreas de carpintería, zapatería, sastrería, panadería, electricidad, radio, televisión, dibujo y artes, entre otras". También hay demanda de capacitación en la maquila, en el tratamiento de la basura, en el respeto y cuidado del medio ambiente y en el manejo y manipulación higiénica de alimentos a los vendedores callejeros. Estos son solo algunos ejemplos de la gran variedad de cursos que demandan los interlocutores entrevistados.

En el futuro, una parte de la demanda de cursos de capacitación pretende ser cubierta por el Instituto Tecnológico de Zacatecoluca (INTECZA). Su objetivo para los próximos años es capacitar a 6000 personas anualmente y ofrecer exactamente los mismos cursos que ofrece el ITCA abarcando toda la zona de la parte baja del río Lema hasta el departamento de Usulután. Para poder realizar estos objetivos va a contar con el profesorado del ITCA y va a recibir apoyo financiero de FEPADE, a través de sus créditos del BID. Cáritas es también otra institución que posee un centro de capacitación fijo en Zacatecoluca y que en el pasado contó con el apoyo de Fepade para dar cursos de capacitación a los desmovilizados, pero actualmente, el local se dedica exclusivamente a dar cursos de corte y confección. Finalmente, el Centro de Capacitación de la Mujer es también un centro fijo de capacitación en Zacatecoluca que está especializado en diversos cursos de capacitación acelerada, con un período máximo de cuatro meses y que ofrece cursos de corte y confección, floristería con piñatería (flores de papel), panificación, electricidad (curso de tres meses) y taquimecanografía

Además de estos tres centros de capacitación, la Fundación Salvadoreña de Apoyo Integral (FUSAI) ofrece programas de desarrollo local en infraestructura y vivienda; y el Centro de Investigaciones Tecnológicas (CIT) ha realizado en la zona capacitaciones en costura, albañilería y procesamiento de frutas. 


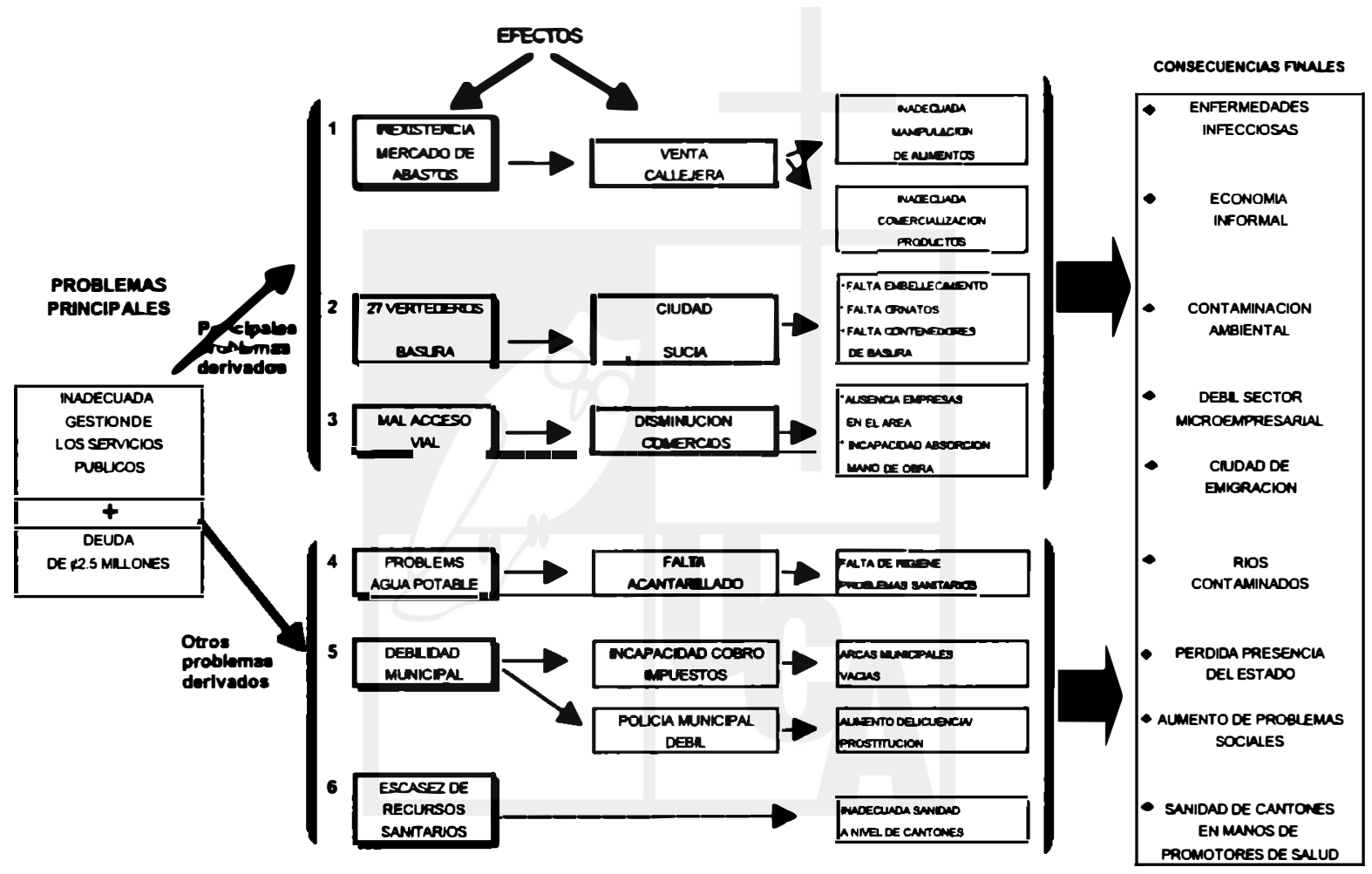




\section{El Pedregal}

\section{A. Estructura problemática}

El Pedregal es un cantón que pertenece al municipio de El Rosario de la Paz y que alberga en su interior a "El Parque de El Pedregal" que es una zona franca en donde se encuentran las mayores empresas maquiladoras extranjeras en El Salvador.

Este Parque Industrial posee un efecto de absorción de gran parte de la mano de obra de los municipios de alrededor. Tal es el caso de los municipios de El Rosario de la Paz, San Pedro Masahuat y San Juan Nonualco. El Rosario de la Paz tiene una extensión de $45.64 \mathrm{~km}^{2}$ y cuatro cantones. San Pedro Masahuat tiene una extensión de $121,39 \mathrm{~km}^{2}$ y 16 cantones y San Juan Nonualco tiene una extensión de $59,65 \mathrm{~km}^{2}$ y 12 cantones.

Los tres municipios que se han visitado en esta zona del Departamento de La Paz tienen unos problemas muy similares. En el mapa de la estructura problemática se observan los dos o tres problemas básicos de cada municipio, entre los que hay que destacar los altos índices de desempleo y el mal acceso por carretera.

De estos problemas básicos generales, hay una serie de problemas derivados que son comunes para los tres municipios analizados: inadecuada recolección de la basura, mala canalización del agua potable, inadecuados servicios de salud, personal docente insuficiente y problemas ambientales. Producto de estos problemas se derivan también una serie de consecuencias: carencia de vertedero de basura, contaminación de las aguas, problemas sanitarios, aislamiento y falta de actividad productiva y comercial.

Además de los problemas genéricos de cada municipio, las instituciones consultadas tienen sus propios problemas específicos. Así, la escuela Fabio Ignacio Maraña de El Rosario de la Paz, pese a ser una Escuela Modelo, sufre de los mismos problemas que el resto de las escuelas rurales del país. Estos jóvenes proceden de una comunidad que no tiene recursos y que no presta mucha atención a la importancia de la educación. Pocos son los alumnos que pasan del sexto o del noveno grado, por lo que los hombres acaban como jornaleros y las mujeres como muchachas de hogar.

En la zona franca del Pedregal hay unas 4300 personas trabajando y esta cifra va a seguir aumentando en el futuro. El $70 \%$ de estos trabajadores son menores de 30 años, $\mathrm{Al}$ parecer, el índice de rotación es bastante más bajo en El Pedregal, que en la zona franca de Export Salva, ya que a diferencia de otros lugares del país donde hay zonas francas, aquí la gente tiene pocas alternativas de empleo. 
Según una encuesta realizada, la mayor parte de los trabajadores. proceden de un radio de 25 a $30 \mathrm{~km}$ a la redonda.. Si se considera solamente las personas que proceden del departamento de $\mathrm{La} \mathrm{Paz}$, el número total de trabajadores es de $2934^{1}$. De los cuales, $555(18,91 \%)$ son de Santiago Nonualco, $490(16,70 \%)$ son de Zacatecoluca y $462(15,74 \%)$ son de El Rosario. Es decir el $51,35 \%$ del total de trabajadores originarios de La Paz procede de estos tres municipios. Llama la atención la poca cantidad de trabajadores (160) procedentes de San Pedro Masahuat, pese a ser un municipio grande, lo cual es un dato más que refleja el grado de aislamiento del municipio a causa de su diff́cil acceso.

A pesar de la creciente importancia de la zona franca de El Pedregal en la generación de empleo en la zona, la agricultura sigue siendo la actividad predominante. Los operarios que trabajan en el sector agrícola, básicamente cultivan maíz y se deben enfrentar a una gran cantidad de problemas ya que no suelen disponer de recursos suficientes para comprar los abonos que necesitan y además, los Bancos les prestan el dinero a unas altas tasas de interés.

\section{B. Iniciativas que se están tomando en la zona}

En San Juan Nonualco, las acciones prioritarias de la Alcaldía son: mejorar la apertura de los caminos vecinales; remodelar los mercados; ayudar a las comunidades de bajos recursos e introducir el agua potable en las colonias que lo necesitan. Por su parte, el objetivo de la Alcaldra de San Pedro Masahuat es conseguir aumentar sus ingresos a través de tasas por el uso del aeropuerto, asf como conseguir solucionar el problema de las canalizaciones del agua y el de la recolección de la basura. A estos grandes objetivos hay que añadir el arreglo de la carretera de acceso al pueblo y la mejora de los caminos de los cantones y de la electrificación general en el municipio. Por último, El Rosario de la Paz también tiene como una de sus principales iniciativas, la recaudación de impuestos en todo el municipio.

\section{H*}

Por otro lado, la intención de los dueños del Parque de El Pedregal es abrir la zona a cualquier tipo de empresas. Actualmente, la mayor parte de las empresas se dedican a la maquila si bien hay ya empresas que trabajan en otros sectores. Por el momento, solo está construido el 35\% de la zona de El Parque, hay por lo tanto, suficiente terreno para seguir expandiéndose. Su objetivo es poder atraer a tres nuevas empresas cada año, además de que las empresas ya instaladas amplíen sus negocios. El Parque de El Pedregal tiene su propia estrategia para el futuro, que pasa por convertir El Parque Industrial de El Pedregal en la Ciudad Industrial

1. Estos datos son solo orientativos ya que se están modificando cada día. 
de El Pedregal. Este proyecto va a hacer que toda la zona de alrededor se desarrolle porque está previsto construir casas para los operarios, con el objetivo de poder alojar en la zona de El Pedregal, a unas 25000 personas. Se prevé que en el futuro vayan a llegar a El Pedregal empresas que demandarán menos mano de obra, pero que serán más estables.

\section{Necesidades de capacitación}

Se ha observado una gran demanda de cursos de capacitación en corte y confección para facilitar la colocación de la gente en la zona franca de El Pedregal. Las empresas ubicadas en El Pedregal siguen necesitando de abundante mano de obra, no solo de operarios sino de personal capacitado en oficios de mantenimiento de maquinaria (mecánicos industriales) y de infraestructura de edificios (carpinteros, electricistas...etc). Por otro lado, también es necesario potenciar los talleres de oficios (costura, corte y confección, floristería, carpintería, albañilería, soldadura eléctrica y tornos y panadería) y apoyar el desarrollo de la microempresa.

Como ya se ha indicado al hablar de Export Salva, las empresas de El Parque de El Pedregal también organizan sus propios cursos de capacitación interna para las personas recién incorporadas. El período de capacitación varía de unas empresas a otras, si bien las empresas más grandes tienen programas de capacitación propios cuya eficacia se ha contrastado a nivel mundial. La situación es diferente para el resto de las empresas que trabajan fuera de la zona franca de El Pedregal, como las cooperativas de pescadores o el sector de la hostelería, que necesitan de apoyo para la capacitación de su personal.

Las empresas ubicadas en El Pedregal que están interesadas en la capacitación externa, ya han empezado a hacer contactos con el ITCA y con Insaforp para que les apoyen en la capacitación de los nuevos operarios. El objetivo estratégico de la gerencia de El Pedregal, es conseguir capacitar a los operarios en los nuevos oficios que demanden las nuevas empresas que se instalen en el Pedregal. Por tal motivo, se van a entablar contactos con Ricaldone, Santa Cecilia y Ciudadela Don Bosco. Además, a través de FUSADES, El Pedregal se ha puesto en contacto con el sector automotriz y con la asociación de juguetes de EEUU con la intención de que se instalen más empresas en el Pedregal.

\section{Conclusiones}

Como se ha podido apreciar en estas páginas, El Salvador necesita aumentar el ṇivel educativo de sus ciudadanos. En este sentido. la capacitación vocacional, además de estar enmarcada dentro de los programas educativos del país, debería ser considerada como una alternativa real y seria a las profesiones universitarias, 
ESTRUCTURA PROBLEMATICA

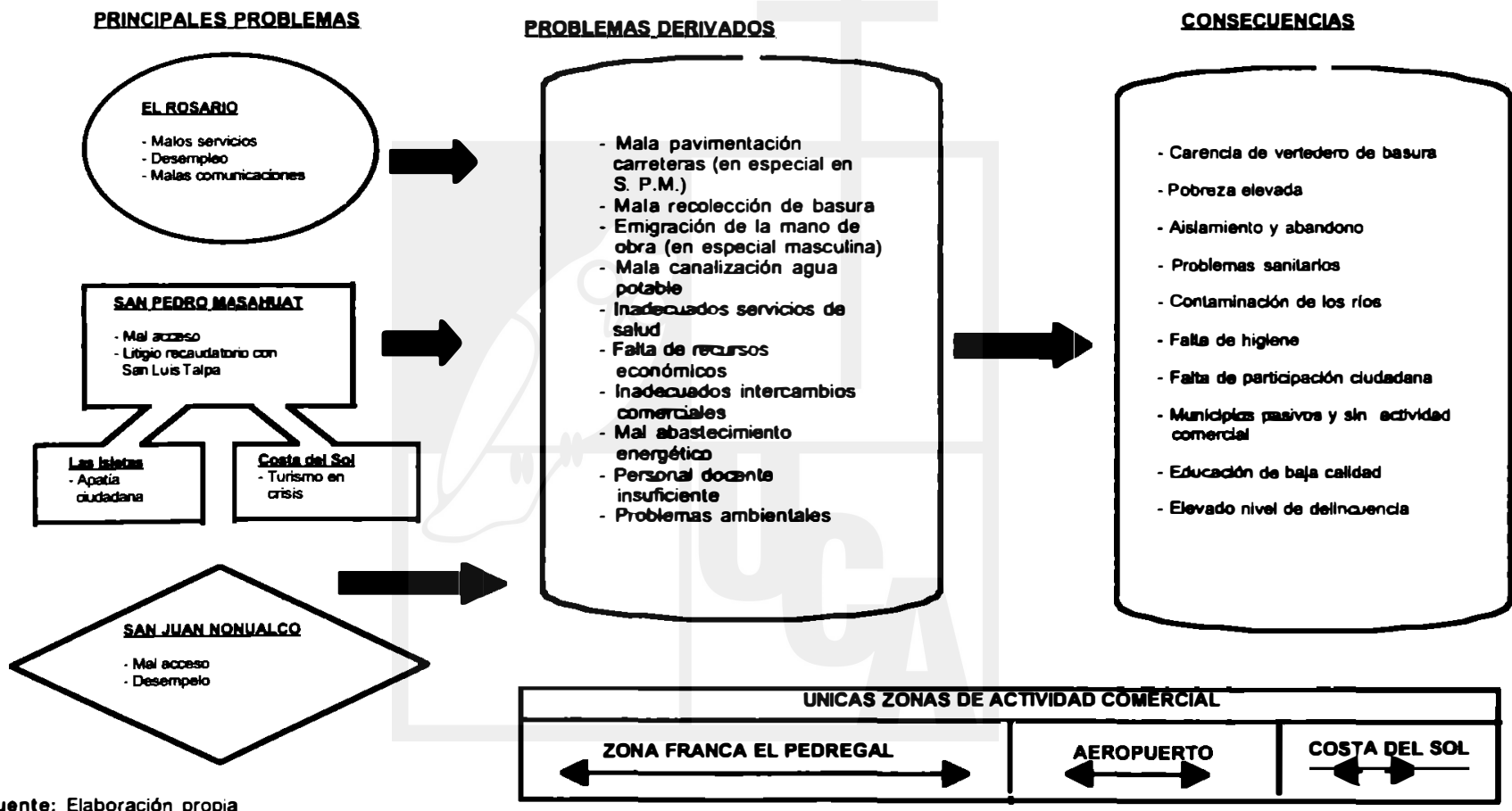


que contribuya al fortalecimiento del tejido institucional y del aparato productivo.

Así pues, hay que potenciar los esfuerzos que incentiven a los jóvenes a seguir estudiando hasta completar su período de educación básica, para que la educación sea una alternativa real al trabajo prematuro; sin embargo, desgraciadamente, se siguen perdiendo muchos recursos humanos capaces, porque los alumnos que estudian en las zonas rurales lo hacen en unas condiciones muy difíciles y abandonan sus estudios antes de llegar al noveno grado.

Por otro lado, la capacitación vocacional debe ayudar a lograr que la gente con menos recursos mejore su nivel de vida y a la vez, debe ser un instrumento para la mejora de la productividad del sector económico en general y del microempresarial en particular. Así pues, una capacitación que no esté contemplada como un mecanismo de inserción laboral permanente en la sociedad, solo generará más frustración.

Es importante que el Insaforp establezca una normativa adecuada para evitar que cada empresa capacitadora interprete la capacitación vocacional con criterios diferentes, para lo cual se deben regular las condiciones para el reconocimiento oficial de los estudios de Formación Profesional, siempre y cuando estos títulos sean otorgados por institutos públicos o privados que reúnan el equipamiento y cuenten con las condiciones y programa integral de formación adecuados..

En este sentido, sería conveniente evitar la proliferación de entidades capacitadoras excesivamente débiles, sin capacidad de gestión y sin ninguna posibilidad de crecimiento, por lo que se debería fomentar que las instituciones capacitadoras se agruparan en consorcios y que trataran de construir centros fijos lo más cercanos posibles a las necesidades de los ciudadanos.

Por otro lado, antes de decidir la capacitación a realizar hay que observar las infraestructuras, la situación de los servicios públicos y las demás condiciones de vida de la gente. Además, hay que determinar si se desea capacitar a personas que ya están trabajando pero que nocesitan completar su formación, con el objetivo de que se fortalezcan así las instituciones; o si desea capacitar a gente desempleada, con el riesgo de que muchas veces no encuentren trabajo, si no se crean los mecanismos de inserción laboral adecuados. Por otro lado, la capacitación que se realice debe estar integrada en los programas de creación y fortalecimiento de las microempresas en su intento porque superen la fase de informalidad y venta callejera y que se aproximen al sector formal de la economía. Para ello, habrá que arbitrar mecanismos adecuados de seguimiento y de Bolsas de Trabajo.

Además, para que la capacitación dé los resultados esperados debe hacerse tras haber dialogado con todos los agentes involucrados. Se deben escuchar las necesidades y deseos de los posibles beneficiarios-meta y también se deben tener en cuenta las potencialidades de la zona y las necesidades de las empresas allí instaladas. Por otro lado, una capacitación sin seguimiento posterior que 
lleve a la inserción laboral de la mayoría de los capacitados, carece de sentido. Para que la capacitación tenga impacto, debe favorecer el desarrollo de comunidades o zonas geográficas concretas, más que beneficiar a individuos aislados.

Tras haber visitado varios cantones en estos municipios y haber hablado con sus líderes comunales, se observa la importancia de contar con la participación ciudadana, especialmente en estos lugares tan apartados. Es solo a través de estos representantes comunales como se puede llegar a los posibles beneficiarios para averiguar lo que desean hacer y en qué quieren capacitarse.

Por último, en cualquier actividad que se realice, es muy conveniente que se mantengan contactos fluidos con las corporaciones locales porque esto favorece la discusión de las fuerzas representativas sobre las prioridades de la inversión; permite conocer mejor como funcionan las comunidades y se logra un mayor compromiso de las autoridades elegidas a nivel local.

En resumen, el fortalecimiento institucional, el aumento de la participación ciudadana, el fomento del empleo y de la microempresa y la organización de cursos de capacitación vocacional deben ser todo un conjunto de mecanismos integrados que contribuyan a potenciar el desarrollo local del país. La capacitación vocacional debe ser pues, un componente más al servicio de un plan general integrado de toda la zona. Un desarrollo económico integrado con la participación de las alcaldías y de los demás agentes económicos y sociales, en el que la capacitación vocacional sea un elemento más, es el mecanismo de descentralización más adecuado para conseguir una verdadero fortalecimiento del Estado a nivel local. Así pues, como se ha podido ver a lo largo de estas páginas, la realidad es muy compleja y hay muchos factores que se deben tener presentes en todo momento.

\section{Bibliografía utilizada}

Agudelo Mejía, Santiago (1993) Terminología básica de formación profesional. OIT. Nicaragua.

Argumedo, José Enrique et alli (1995): Los conflictos laborales en El Salvador en el contexto de un Estado de Derecho. Eds. Konrad Adenauer Stiftung y UCA. Imprenta Criterio. San Salvador.

Briones, Carlos (1996): ¿Continuidad o transformación?. El sector informal urbano 1988-1994. San Salvador

Briones, Carlos (1996): Problemas y perspectivas de la microempresa. San Salvador

Briones, Carlos (1996): Red de programas de apoyo a la micro y a la pequeña empresa. San Salvador

Caja de Crédito (1996): "Memoria de Labores". Colón. 
Caja de Crédito (1996): "Memoria de Labores". Puerto de La Libertad

Caja de Crédito (1996): "Memoria de Labores". Zacatecoluca.

Ciudadela don Bosco, (-): "Centro de información Profesional" Revista. San Salvador.

Colbm (1996): El Libro Blanco de la Microempresa. San Salvador.

Concejo Municipal, (1997): "Plan de trabajo del municipio del Puerto de La Libertad".

Concejo Municipal, (1997): "Objetivos generales del plan para los primeros 100 días" Municipio de Zacatecoluca.

Concejo Municipal, (1997): "Plataforma Municipal" Municipio de Zacatecoluca.

CREFAC, (1995): "Memoria de Labores" San Salvador.

ENA, (1997): "El sistema de educación no formal y las acciones de capacitación de la ENA para 1997".

FACOPADES, (1997): "Proyecto de desarrollo pesquero artesanal". Proyecto presentado al gobierno japonés.

FEPADE, (1996): "Memoria de Labores". San Salvador.

FMLN (1997): "Plataforma municipal para el cambio"

FORMARE (1997):" Hacia un sistema adecuado de formación profesional". Ponencias del seminario-taller. San Salvador

Fundación 16 de enero, (1995): Boletín informativo. Diversos números. San Salvador.

Fundación 16 de enero, (1996): De la esperanza a la realidad. San Salvador.

GENESISS, (1997): "Inserción de Jóvenes en el empleo. Cuaderno de Experiencias". San Salvador.

GENESISS, (1997): "Retos de inserción laboral para jóvenes". Ponencias del seminario-taller. San Salvador.

Gobierno de El Salvador, (1996): Cuantificación y localización de necesidades básicas. Datos censales. Departamento de La Libertad. San Salvador.

Gobierno de El Salvador, (1996): Cuantificación y localización de necesidades básicas. Datos censales. Departamento de La Paz. San Salvador.

INTECZA. (1997): "Catálogo de servicios". Zacatecoluca.

ITCA, (1996): "Memoria de Labores". Santa Tecla.

Lohmar-Kuhnle, Cornelia (1994): Occupation-oriented Training and Education for Target Groups from the Informal Sector. Nomos Verlagsgesellschaft. Baden-Baden. Alemania.

Ministerio de Economía, (1995): Censos Nacionales V de Población y IV de Vivienda Departamento de La Libertad. Tomo V. San Salvador.

Ministerio de Economía, (1995): Censos Nacionales V de Población y IV de Vivienda Departamento de La Paz. Tomo VIII. San Salvador.

Ministerio de Economía, (1995): Censos Nacionales V de Población y IV de Vivienda Departamento de San Salvador. Tomo VI. San Salvador

Ministerio de Obras Públicas, (-): Monografias de departamento y municipios 
de: La Libertad. Instituto Geográfico Nacional. San Salvador

PNUD, (1992): Directorio de Instituciones Privadas de Desarrollo. San Salvador. PNUD, (1995): Cooperación técnica y financiera para El Salvador, según informada por los cooperantes. 1992-1996. San Salvador.

PNUD, (1997): Nota de consulta para la República de El Salvador. San Salvador.

Pro Foco Microempresarial, (-): Quetzaltenango, Totonicapán y Retalhuleu. Región VI Sur-Occidente. GTZ. Guatemala.

Pro Foco Microempresarial, (1996) Asesoría técnica en desarrollo económico local. Microrregión Quetzaltenango. GTZ. Guatemala

PRO FOCO MICROEMPRESARIAL, (1996) Impacto y necesidades de capacitación técnico-empresarial. Región Sur-Occidente. GTZ. Guatemala

Pro Foco Microempresarial, (1996) Presentación de Profoco. Resumen ejecutivo. GTZ. Guatemala

Pro Foco Microempresarial, (1997) Presentación del método VIVA. GTZ. Guatemala

PRONAFORP, (1996): Estudio de las características y determinación de necesidades de la formación profesional del sector informal urbano en El Salvador. San Salvador.

Proyecto SRN/GTZ (1996):" Programa de integración y fomento de empleo". GTZ. San Salvador

Proyecto SRN/GTZ (1996):" Programa de integración y fomento de empleo. Plan de Acción. Informes de avance". GTZ. San Salvador

TAUSKI, Curta (1976) Conducción y organización BCE. Argentina

TROSSE, Ralph (1996): Elaboración de una estrategia para el departamento de Ahuachapán Informe. GTZ. San Salvador

Universidad Albert Einstein, (1996): Estudio de factibilidad económica y un anteproyecto urbano-arquitectónico para el centro generador de un polo de desarrollo en el valle de San Andrés". San Salvador.

Vanderwegen, Eric (1996): "Propuesta de concepto de trabajo". GTZ. San Salvador 